\title{
Pilot study: deficiency of mannose-binding lectin-dependent lectin pathway, a novel modulator in outcome from pancreatic islet auto-transplantation
}

\author{
Wen Yuan Chung ${ }^{1}$, Cristina A. Pollard ${ }^{1}$, Cordula Stover ${ }^{2}$, Bashoo Naziruddin ${ }^{3}$, Rohan Kumar ${ }^{1}$, \\ John Isherwood ${ }^{1}$, Eyad Issa ${ }^{1}$, Marlon F. Levy ${ }^{3}$, Giuseppe Garcea ${ }^{1}$, Ashley R. Dennison ${ }^{1}$ \\ ${ }^{1}$ Department of Hepatobiliary and Pancreatic Surgery, Leicester General Hospital, Leicester, UK; ${ }^{2}$ Department of Infection, Immunity and \\ Inflammation, University of Leicester, Leicester, UK; ${ }^{3}$ Baylor Research Institute, Dallas, TX, USA \\ Contributions: (I) Conception and design: C Stover, AR Dennison; (II) Administrative support: None; (III) Provision of study materials or patients: \\ None; (IV) Collection and assembly of data: WY Chung, CA Pollard, B Naziruddin, R Kumar, J Isherwood, E Issa, MF Levy, G Garcea; (V) Data \\ analysis and interpretation: WY Chung, CA Pollard, B Naziruddin, R Kumar, J Isherwood, E Issa, MF Levy, G Garcea; (VI) Manuscript writing: All \\ authors; (VII) Final approval of manuscript: All authors. \\ Correspondence to: Dr. Wen Yuan Chung. Department of HPB Surgery, Leicester General Hospital, Gwendolen Road, Leicester LE5 4PW, UK. \\ Email: wenchung813@btinternet.com.
}

Background: Numerous factors influence pancreatic islet survival following auto-transplantation. Of these, the host immune response in the early peri-operative period is one of the most important. In this study we investigated the role of the mannose-binding lectin (MBL)-dependent pathway in a group of total pancreatectomy (TP) islet auto-transplantation (TPIAT) patients and classified them as competent or deficient in MBL activity. Complement pathway activities, MBL protein and inflammatory cytokine concentrations were evaluated from eleven pancreatic islet auto-transplant patients from two institutions.

Methods: Eleven patients from two institutions were prospectively recruited. Serum was screened at different time points for 29 different cytokines and compared according to their MBL deficient or competent status. Twelve patients from previous TPIAT patients also underwent screening of MBL pathway activity.

Results: A total nine of twenty three patients (39\%) were MBL pathway deficient. MCP-1, IL-7 and IL1a concentrations were significantly lower in the MBL deficient cohort compared to the normal MBL group ( $\mathrm{P}=0.0237,0.0001$ and 0.0051 respectively). IL-6 and IL-8 concentrations were significantly raised in the normal MBL group. MBL functional activity was lower in insulin-independent group compared to the insulin-dependent group.

Conclusions: Complement activation is an important, possibly damaging response during intra-portal islet infusion. MBL pathway deficiency appears common in this population and the cytokine response was attenuated in MBL pathway deficient patients. Therapeutic MBL pathway blockade during and following islet auto-transplantation (IAT) may improve islet survival and function and thereby clinical outcome.

Keywords: Islet auto-transplantation (IAT); mannose-binding lectin (MBL)

Submitted Sep 19, 2019. Accepted for publication Nov 29, 2019.

doi: 10.21037/atm.2020.02.19

View this article at: http://dx.doi.org/10.21037/atm.2020.02.19

\section{Introduction}

Islet auto-transplantation (IAT) is a procedure used to prevent or ameliorate postoperative diabetes in patients undergoing total pancreatectomy (TP). Although recently introduced into clinical practice, IAT is currently actively performed in the United States (1-3), United Kingdom (4), Switzerland (5) and South Korea (6), with other centres around the world developing their own islet program. 
Results of a recent meta-analysis confirmed the overall efficacy of IAT in the short term (7). For this reason numerous insurance companies now fund the procedure when undertaken with TP to treat intractable pain in nondiabetic patients (or C-peptide positive diabetic patients) with chronic pancreatitis (8). However, early positive results are generally counterbalanced by unpredictable longterm outcomes due to the effects of numerous and poorly understood factors. Amongst these, the inflammatory response produced during and immediately after islet infusion probably contributes to the long-term loss of graft survival and function (9).

The complement cascade is one of the major activators and amplifiers of inflammation through the stimulation of a non-specific immune response and the production of pro-inflammatory cytokines. In clinical transplantation, the activation of complement and the consequent inflammatory reaction exerts a significant influence on graft survival (10) including islet transplants (11). The complement system consists of the classical (CP), alternative (AP) and mannosebinding lectin (MBL) pathways of activation (12). Congenital deficiencies have been described for all pathways (13) but MBL deficiency is the most common (14). This condition produces recurrent infections (15) and decreased inflammatory response to ischemic-reperfusion injuries $(16,17)$. Therefore, in the setting of clinical transplantation; MBL-deficiency could be beneficial because the attenuated immune response produced would affect autografts less than in MBL-competent patients, with a potential for better graft survival and long-term function.

The purpose of our study is to investigate the inflammatory response elicited in MBL-deficient patients and compare it to that of MBL-competent patients undergoing TP and IAT and compare this with graft survival and function post-operatively

\section{Methods}

\section{Patients}

Twelve patients who had undergone previous total pancreatectomy islet auto-transplantation (TPIAT) in Leicester were recruited to the study and a further eleven patients were prospectively recruited from the Leicester General Hospital (LGH; Leicester, United Kingdom) and the Baylor Research Institute (BRI; Dallas, United States). This study was approved by the institutional review board (IRB), and written informed consent was obtained from all patients included. The authors are accountable for all aspects of the work in ensuring that questions related to the accuracy or integrity of any part of the work are appropriately investigated and resolved.

\section{Islet isolation and transplantation}

In the Leicester series, islets were prepared and infused as previously described (18). Pancreas was digested with Neutral Protease NB GMP Grade in combination with purified Collagenase NB 1 GMP Grade (SERVA Electrophoresis GmbH, Heidelberg, Germany). Unpurified whole pancreatic digest was suspended in M199 transplant media containing 20\% human serum albumin. Islets were prepared while the surgeons completed the enteroenterostomy and choledochojejunostomy reconstruction (19). Immediately prior to the transplant, the patients received 5,000 $\mathrm{U}$ heparin intravenously. Islets were infused into the portal vein via an umbilical vein (with heparin) over 20-30 minutes (20). During the islet cell infusion the portal pressures were continuously monitored to ensure that the levels reached did not exceed $20 \mathrm{mmHg}$.

In the Baylor series, islets were prepared and infused as previously described (21). Pancreas was digested with either Liberase $^{\mathrm{TM}}$ MTF with Thermolysin ${ }^{\mathrm{TM}}$ (Roche, Indianapolis, United States) or Collagenase NB 1 GMP Grade (SERVA Electrophoresis GmbH, Heidelberg, Germany). Isolated islets were infused into the portal vein via the mesenteric vein with heparin $(70 \mathrm{U} / \mathrm{kg}$ body weight) over 30 to 60 minutes while the patients were under general anaesthesia. During islet infusion, portal vein pressure was monitored intermittently. If portal vein pressure exceeded $20 \mathrm{mmHg}$, the infusion of islets was stopped until portal vein pressure decreased.

The islet yield was converted into a standard number of islet equivalents (IEQ), with the diameter standardized to $150 \mu \mathrm{m}$. Islet viability in the final product was evaluated with fluorescein diacetate/propidium iodide staining.

\section{Serum tests}

Serum samples were obtained retrospectively at follow up baseline levels were obtained at preoperatively, prior to islet infusion, during islet infusion, at the completion of islet infusion. Subsequently, serum samples were obtained at 1 hour, 3 hours, 6 hours, 24 hours, 3 days, 5 days, and 7 days post islet infusion. Serum samples were stored at $-80^{\circ} \mathrm{C}$ until assayed. 
The Wieslab ${ }^{\circledR}$ Complement system Screen (EuroDiagnostica, Malmö, Sweden) was used according to the manufacturer instructions. The following kits were used for MBL protein evaluation: Human MBL ELISA kit HK3223 (Hycult Biotech, Uden, The Netherlands), and as controls for assay: MBL standard serum SER101 and MBL oligomer deficient serum, B/B genotype SER102, from Antibodyshop (BioPorto Diagnostics A/S, Gentofte, Denmark).

Concentrations of cytokines and chemokines were determined by measuring serum samples in a Luminex 200 (Millipore, Billerca, Massachusetts, USA) using xMAP technology. The bead assay was performed according to the manufacturer's instructions. Markers were: interferon alpha (IFN- $\alpha$ ), interferon gamma (IFN- $\gamma$ ), interleukin-10 (IL-10), interleukin-12p40 (IL-12p40), interleukin-12p70 (IL-12p70), interleukin-13 (IL-13), interleukin-15 (IL15), interleukin-17 (IL-17), interleukin-1ra (IL-1ra), interleukin-1 alpha (IL-1 $\alpha$ ), interleukin-1 beta (IL-1 $\beta$ ), interleukin-2 (IL-2), interleukin-3 (IL-3), interleukin-4 (IL4), interleukin-5 (IL-5), interleukin-6 (IL-6), interleukin-7 (IL-7), interleukin-8 (IL-8), Epidermal growth factor (EGF), Eotaxin, Granulocyte colony-stimulating factor (G-CSF), Granulocyte-macrophage colony-stimulating factor (GM-CSF), Vascular endothelial growth factor (VEGF), Monocyte Chemotactic Protein-1 (MCP-1), macrophage inflammatory protein 1 alpha (MIP-1 $\alpha$ ), macrophage inflammatory protein 1 beta (MIP-1 $\beta$ ), Tumor necrosis factor-alpha (TNF- $\alpha$ ) and Tumor necrosis factorbeta (TNF- $\beta$ ).

\section{Statistical analysis}

All data were initially entered into an Excel database (Microsoft, Redmond, Washington, United States) and the analysis was performed using the Statistical Package for the Social Sciences Windows, version 13.0 (SPSS, Chicago, Illinois, USA). Descriptive statistics consisted of the mean and standard deviation for parametric distributions and median and range for non-parametric distributions after confirmation with the Kolmogorov-Smirnov test and histograms.

Comparisons over time were performed with the ANOVA for repeated measures for parametric variables or Friedman for non-parametric variables. Comparison among MBL competent and MBL deficient patients was performed with ANOVA for repeated measures for parametric variables and the Mann-Whitney test for non-parametric variables. $\mathrm{P}$ values of $<0.05$ were considered statistically significant.

\section{Results}

\section{Patients}

In the LGH group, the whole pancreatic digest was used without purifying the islets, in the BRI group islets were purified in 5 cases and not purified in 3 cases (Table 1). The amount of transplanted IEQ was not different between the LGH and BRI. Four patients (40\%) were identified with MBL pathway activity deficiency and one patient had very low MBL activity (Table 1; Figure 1A). Two MBL pathway deficiency patients were associated with MBL protein deficiency (Figure 1B). Retrospectively, twelve patients from Leicester series were recruited from previous TPIAT. Five/ twelve $(41.7 \%)$ were MBL pathway deficiency (Table 2; Figure 1A). There were 5/9 (55.6\%) insulin free in MBL deficient patients compared to $4 / 14$ (28.6\%) insulin free in MBL competent patients (Tables 1,2).

\section{Complement activity}

No significant differences were present in the CP and AP activities between MBL deficient vs. competent patients $(\mathrm{P}=0.167$ and $\mathrm{P}=0.053$ respectively). There was a significant difference MBL pathway activity between MBL deficient $v$. competent patients $(\mathrm{P}<0.001)$. The $\mathrm{CP}$ activity was reduced, compared to baseline levels, from the completion of islets infusion $(\mathrm{P}<0.001)$ to the $3^{\text {rd }}$ postoperative day when it recovered to preoperative values (Figure $2 A$ ). The MBL activity was reduced, compared to baseline levels, before the islets infusion $(\mathrm{P}<0.05)$ to the $4^{\text {th }}$ postoperative day when it recovered to preoperative values (Figure $2 B$ ). The AP activity was reduced, compared to baseline levels, before the islets infusion $(\mathrm{P}<0.05)$ to the $3^{\text {rd }}$ postoperative day when it recovered to preoperative values (Figure $2 C$ ).

\section{Cytokines with changes between MBL competent vs. deficient patients}

IL-6 concentrations were raised in the normal MBL group but not statistically significant compared to MBL deficient group ( $\mathrm{P}=0.0828$ ) (Figure 3A). However, IL-6 level rose significantly in the normal group from its baseline before the islet infusion until the 1 st postoperative day $(\mathrm{P}<0.001)$. MCP-1 concentrations were raised significantly on the $1^{\text {st }}$ day $(\mathrm{P}<0.001)$ and MCP-1 levels were significantly lower in MBL deficient vs. competent patients $(\mathrm{P}=0.0237)$ (Figure $3 B)$. Lower concentrations in the MBL deficient patients, compared with MBL competent ones, were found for IL- 


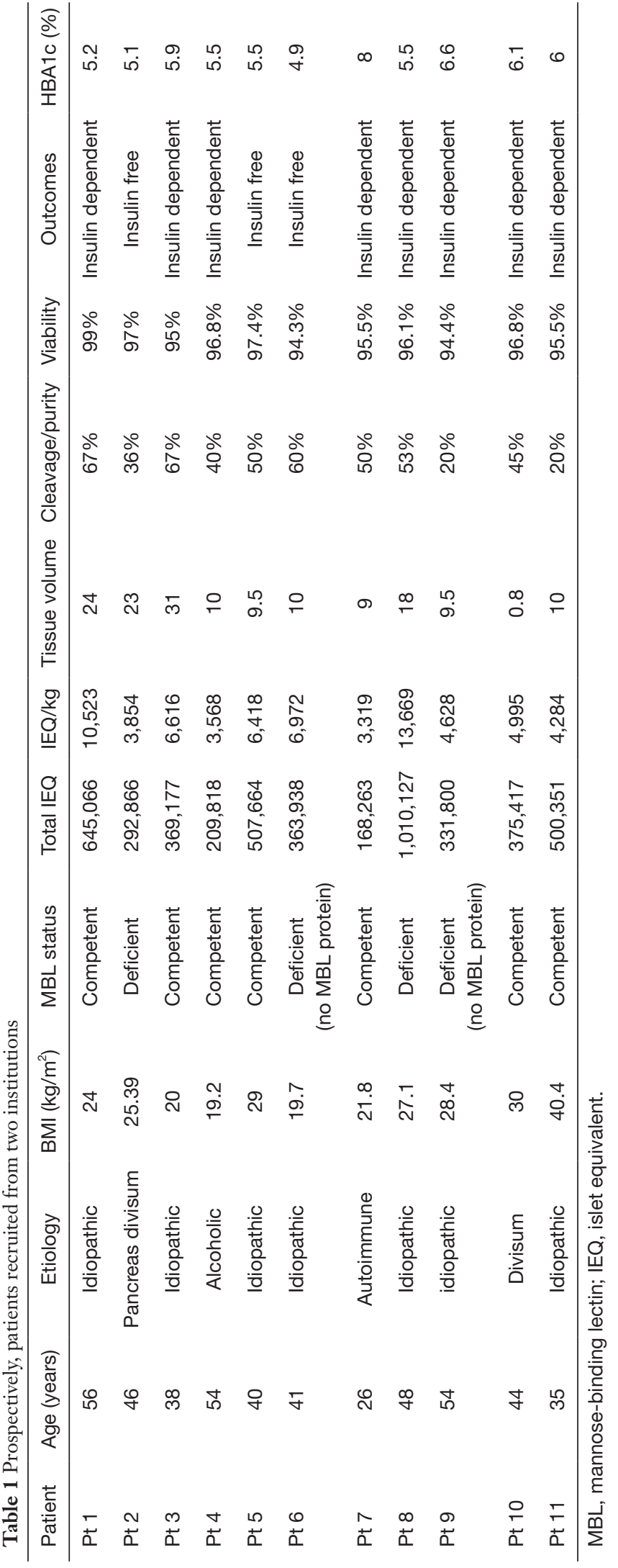

$1 \alpha(\mathrm{P}=0.0051)$ (Figure 3C). IL-8 increased significantly compared to baseline levels before the islet infusion $(\mathrm{P}<0.001)$ until the $3^{\text {rd }}$ postoperative day where it recovered to preoperative values, but there were not statistically different between both groups $(\mathrm{P}=0.11)$ (Figure 3D). IL-7 concentrations were raised significantly in the normal MBL group compared to MBL deficient group ( $\mathrm{P}=0.0001)$ (Figure 3E).

\section{Cytokines with/without changes over time and between MBL competent vs. deficient patients (Table 3)}

IL-15 concentrations were significantly raised from the $1^{\text {st }}$ postoperative hour to the $3^{\text {rd }}$ postoperative day $(\mathrm{P}<0.001)$. GM-CSF concentrations were significantly elevated compared to baseline levels only at the $3^{\text {rd }}$ postoperative hour $(\mathrm{P}<0.05)$. Compared to values before islet infusion, EGF concentrations significantly decreased during the infusion until the $3^{\text {rd }}$ postoperative day included in the MBL competent patients $(\mathrm{P}<0.001)$. IL-6, IL-15, EGF, GMCSF and MCP-1 concentrations were significantly lower in MBL deficient $v s$. competent patients $(\mathrm{P}<0.001)$. Lower concentrations in the MBL deficient patients, compared with MBL competent ones, were found for Eotaxin $(\mathrm{P}<0.001)$, IL-1 $\alpha(\mathrm{P}<0.001)$, IL-2 $(\mathrm{P}<0.001)$, IL-3 $(\mathrm{P}<0.001)$, IL-5 $(\mathrm{P}<0.05)$, TNF- $\beta(\mathrm{P}<0.001)$. Higher concentrations were present only for IL-17 $(\mathrm{P}<0.001)$. G-CSF increased significantly compared to baseline levels before the islet infusion $(\mathrm{P}<0.001)$ until the $3^{\text {rd }}$ postoperative day where it recovered to preoperative values. Similar results were achieved for IL-8 $(\mathrm{P}<0.001)$. For IL-10 the significant increase compared to baseline levels was present only at the completion of the islet infusion $(\mathrm{P}=0.001)$ and 15 minutes after $(\mathrm{P}=0.005)$. At one hour from the end of the operation, the difference was not significant $(\mathrm{P}=0.293)$. For TNF- $\alpha$ the increase compared to baseline was significant from the $3^{\text {rd }}$ postoperative hour $(\mathrm{P}=0.018)$ onwards until the $7^{\text {th }}$ postoperative day $(\mathrm{P}=0.001)$. IL- $1 \beta$ concentration was not significantly different among groups $(\mathrm{P}=0.299)$ and over time compared to baseline levels $(\mathrm{P}=0.865)$. Similar results were found for IL-4 (groups $\mathrm{P}=0.414$; time $\mathrm{P}=0.532$ ), IL-5 (groups $\mathrm{P}=0.268$; time $\mathrm{P}=0.181$ ), IL- 10 (groups $\mathrm{P}=0.589$; time $\mathrm{P}=0.067$ ), IL-12p40 (groups $\mathrm{P}=0.505$; time $\mathrm{P}=0.673$ ), IL-12p70 (groups $\mathrm{P}=0.171$; time $\mathrm{P}=0.967$ ), IL-13 (groups $\mathrm{P}=0.059$; time $\mathrm{P}=0.515$ ), IFN $\alpha$ (groups $\mathrm{P}=0.520$; time $\mathrm{P}=0.992$ ), IFN- $\gamma$ (groups $\mathrm{P}=0.08$; time $\mathrm{P}=0.595$ ), $\mathrm{MIP}-1 \alpha$ (groups $\mathrm{P}=0.288$; time $\mathrm{P}=0.937$ ), $\mathrm{MIP}-1 \beta$ (groups $\mathrm{P}=0.571$; time $\mathrm{P}=0.105$ ), VEGF (groups $\mathrm{P}=0.218$; time $\mathrm{P}=0.128$ ). 

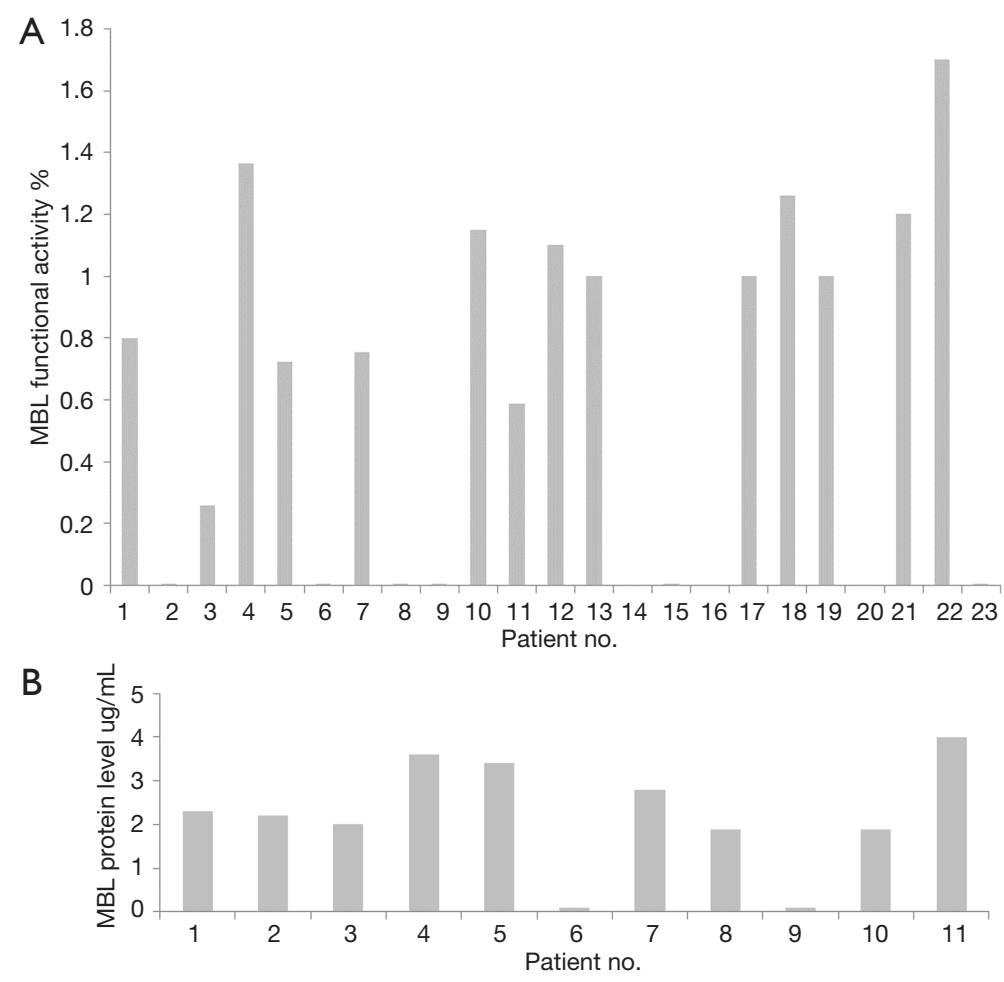

Figure 1 Shows pre-operative MBL functional activity and protein level. (A) MBL pathway activity assay. Pt 1-3 (Leicester General Hospital), Pt 4-11 (Baylor Research Institute) and Pt12-Pt23 (LGH series). (B) MBL protein ELISA assay in islet auto transplant patients. Pt 1-3 (Leiceter General Hospital), Pt 4-11 (Baylor Research Institute). MBL, mannose-binding lectin.

Table 2 Retrospectively recruited from previous TPIAT Leicester series

\begin{tabular}{|c|c|c|c|c|c|c|c|c|}
\hline Patient & Age (years) & Etiology & BMI $\left(\mathrm{kg} / \mathrm{m}^{2}\right)$ & MBL status & Total IEQ & IEQ/kg & Cleavage/purity & Outcomes (1 year) \\
\hline Pt 13 & 43 & Idiopathic & 22.86 & Competent & 57,296 & 954.93 & $18 \%$ & Insulin free \\
\hline Pt 14 & 38 & alcohol & 20.45 & Deficient & 139,420 & 2,359 & $12 \%$ & Insulin free \\
\hline Pt 15 & 43 & Idiopathic & 29.65 & Deficient & 607,822 & $8,008.19$ & $68 \%$ & Insulin free \\
\hline Pt 17 & 54 & Idiopathic & 23.95 & Competent & 645,066 & $10,523.1$ & $67 \%$ & Insulin (12 units) \\
\hline Pt 18 & 45 & Pancreas divisum & 25.39 & Competent & 290,000 & $3,853.5$ & $36 \%$ & Insulin free \\
\hline Pt 19 & 43 & Idiopathic & 20.23 & Competent & 217,500 & 5,330 & $18 \%$ & Insulin (10 units) \\
\hline Pt 20 & 34 & Idiopathic & 24.15 & Deficient & 369,177 & $6,616.08$ & $67 \%$ & Insulin (18 units) \\
\hline Pt 23 & 41 & alcohol & 26.05 & Deficient & 284,592 & 3,298 & $40 \%$ & Insulin free \\
\hline
\end{tabular}

TPIAT, total pancreatectomy islet auto-transplantation; IEQ, islet equivalent. 

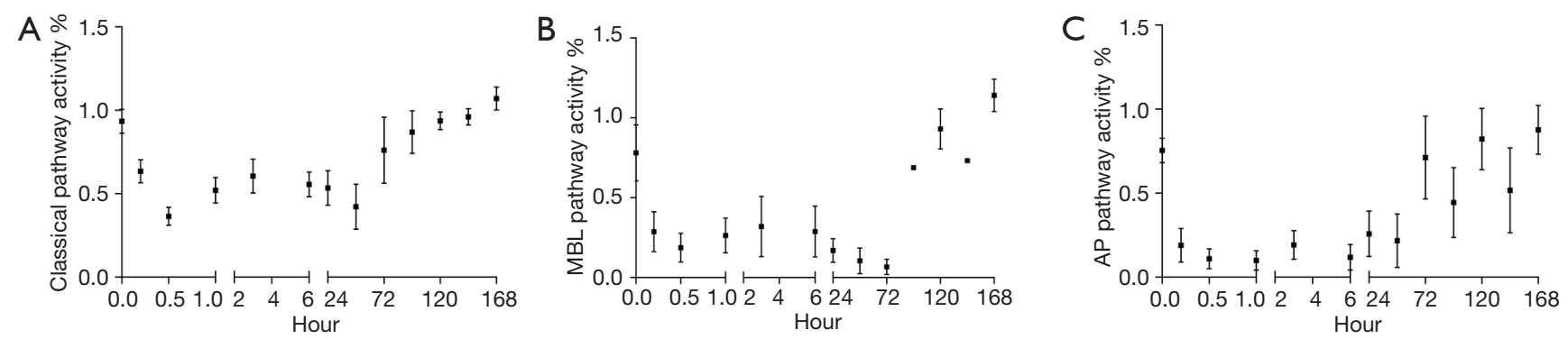

Figure 2 Complement activities over time (A,B,C). Patients with no MBL pathway activity have been removed. MBL, mannose-binding lectin.
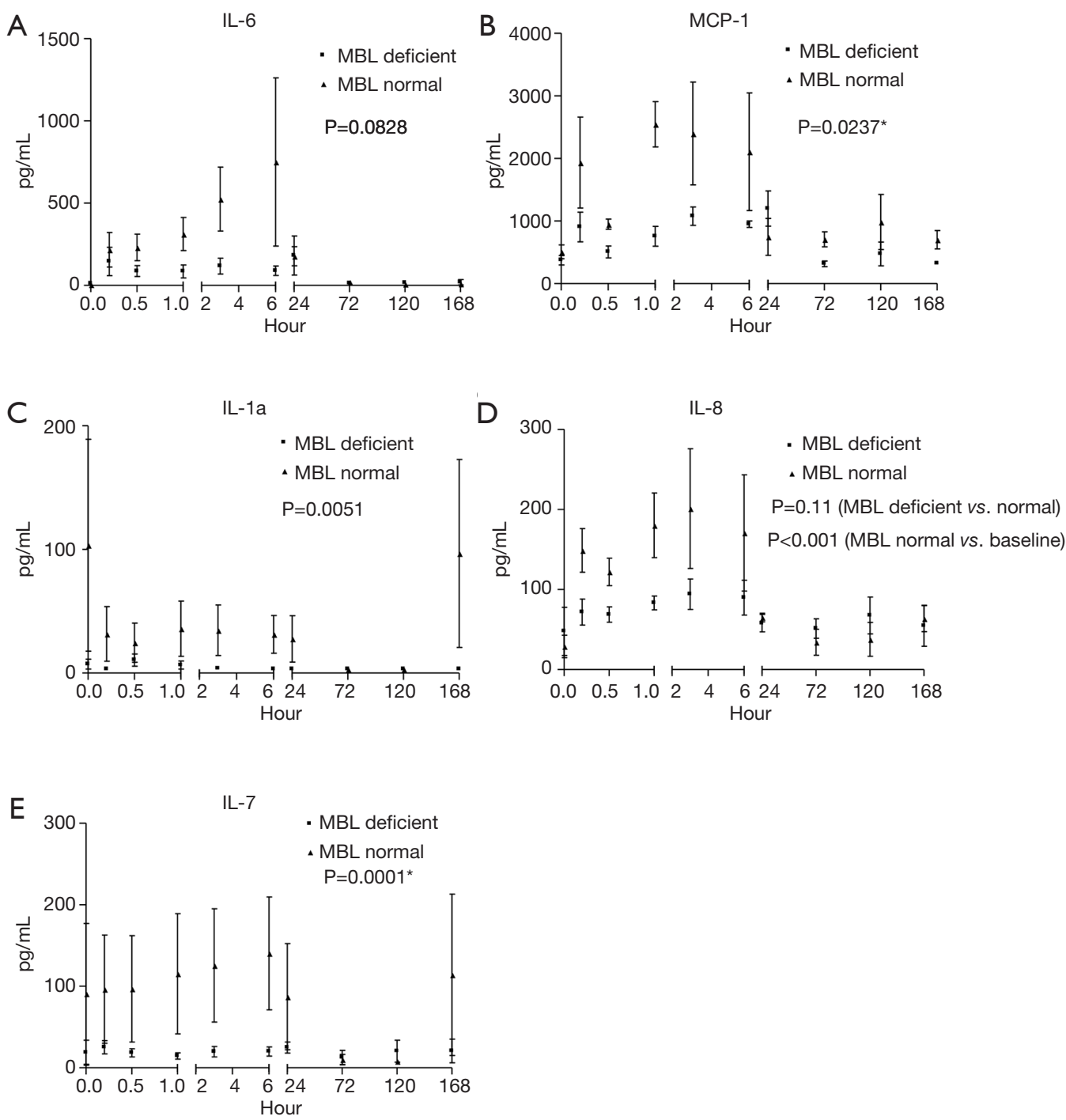

Figure 3 Comparison of IL-6 (A), MCP-1 (B), IL-1a (C), IL-8 (D) and IL-7 (E) cytokine levels between MBL deficient and intact groups and over time. * $\mathrm{P}<0.05$. IL-6, interleukin-6; MCP-1, monocyte chemotactic protein-1; IL-8, interleukin-8; IL-7, interleukin-7; MBL, mannose-binding lectin. 
Table 3 Schematic summary of cytokine modifications

\begin{tabular}{lcc}
\hline \multirow{2}{*}{$\begin{array}{l}\text { Differences } \\
\text { over time }\end{array}$} & No & Differences among groups \\
\cline { 2 - 3 } No & $\mathrm{IL}-1 \beta, \mathrm{IL}-4, \mathrm{IL}-5, \mathrm{IL}-10, \mathrm{IL}-12 \mathrm{p} 40, \mathrm{IL}-12 \mathrm{p} 70, \mathrm{IL}-13, \mathrm{IFN}-\alpha$, IFN- $\gamma$, & Eotaxin, IL-1 $\alpha$, IL-2, IL-3, IL-5, TNF- $\beta$, IL-17 \\
& MIP-1 $\alpha$, MIP-1 $\beta$, VEGF \\
Yes & G-CSF, IL-8, IL-10, TNF- $\alpha$ & IL-6, MCP-1, IL-15, GM-CSF, EGF \\
\hline
\end{tabular}

IL-2, interleukin-2; IL-3, interleukin-3; IL-4, interleukin-4; IL-5, interleukin-5; IL-6, interleukin-6; IL-8, interleukin-8; IL-10, interleukin-10; IL-13, interleukin-13; IL-15, interleukin-15; IL-17, interleukin-17; IFN- $\alpha$, interferon alpha; IFN- $\gamma$, interferon gamma; MIP-1 $\alpha$, macrophage inflammatory protein 1 alpha; MIP-1 $\beta$, macrophage inflammatory protein 1 beta; VEGF, Vascular endothelial growth factor; G-CSF, granulocyte colony-stimulating factor; TNF- $\alpha$, tumor necrosis factor-alpha; TNF- $\beta$, tumor necrosis factor-beta; MCP-1, monocyte chemotactic protein-1; GM-CSF, granulocyte-macrophage colony-stimulating factor; EGF, epidermal growth factor.
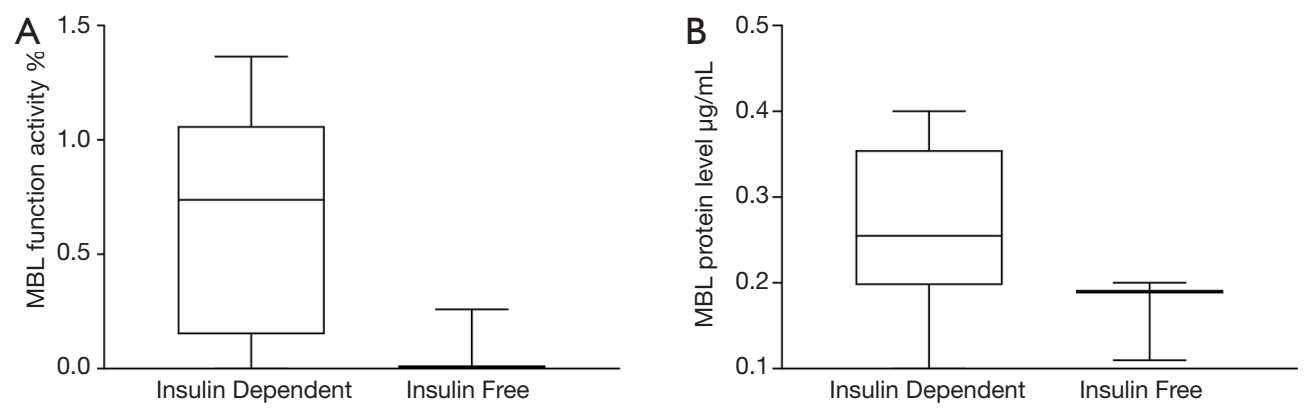

Figure 4 Differences observed between the deficiency of MBL activity and MBL protein groups in achieving insulin-independence following pancreatic islet auto-transplantation. (A) MBL functional activity in insulin-dependent and insulin-free groups. (B) MBL protein level in insulin-dependent and insulin-free groups. MBL, mannose-binding lectin.

\section{Correlations with insulin-free or insulin-dependent outcome after IAT with MBL deficient patients}

A total of 9/23 (39\%) TPIAT patients were MBL deficiency. When comparing outcomes after IAT, no statistically significant differences in MBL functional activity deficiency compared to normal were seen between the two groups (nonparametric Fisher test $\mathrm{P}=0.089$ ). MBL functional activity was seven-fold lower in the insulin free group compared to insulin dependent group (Figure 4A). MBL protein level was nearly half $0.167 \pm 0.049 \mu \mathrm{g}$ in the insulin free group compared to $0.265 \pm 0.099 \mu \mathrm{g}$ in the insulin dependent group (Figure 4B).

\section{Discussion}

Complement plays an important role in islet transplantation. It is a part of the instant blood-mediated inflammatory reaction (IBMIR) at the time of intra-portal transplantation which involves the coagulation and complement cascades.
Here we have studied complement activation and deficiency in a cohort of islet auto-transplanted patients and the relationship with inflammation.

Complement activation is a feature in ischemic reperfusion injury during organ transplantation $(22,23)$. In liver transplantation, significantly elevated $\mathrm{C} 3 \mathrm{a}$ and SC5b9 levels in the absence of elevated levels for C4d suggested a predominant engagement of the alternative pathway of complement activation (22). This reinforced the finding in our cohort of a MBL pathway activity deficiency rate of $9 / 23$ (approx. $40 \%$ ). MBL deficiency occurs in $5-30 \%$ of the general population (14). MBL pathway deficiency is the most common complement pathway deficiency. Many reports have shown the different components deficient in the MBL pathway of which MBL protein deficiency is one of the most common. Deficiency is linked to recurrent infections in children (24). The MBL gene has single nucleotide polymorphisms (SNPs) (25). Therefore, the level of MBL in the blood varies according to whether the 
individual is heterozygous or homozygous $(26,27)$. Two patients with presence of MBL protein and MBL pathway activity deficiency could indicate non functionality of the oligomerisation of MBL or other MBL pathway component deficiencies. Mannan-binding lectin-associated serine portease-2 (MASP-2) and L-ficolin (ficolin-2) are among the other components sometimes found deficient in MBL pathway activity $(28,29)$.

In this study, we demonstrated that complement activation occurred immediately after surgery. Complement activation has previously been considered to be a short-lived transient innate immune response (22), but our data shows that it can, in fact, persist for several days postoperatively. Complement activation increases $\mathrm{C} 3 \mathrm{a}$ and $\mathrm{C} 5 \mathrm{a}$ which in turn triggers the pro-inflammatory response potentially causing additional damage to the islet graft (29).

There are many reports on the expression of a great variety of inflammatory mediators in islet transplantation, but this is the first report on the relationship between complement deficiency and its effect on inflammatory mediators. As previously described, MBL pathway deficiency is the commonest complement pathway deficiency. We examined 29 inflammatory markers of which 5 demonstrated reduced concentration in the MBL pathway deficient patients. MCP-1 was significantly reduced in the $\mathrm{MBL}$ deficient group $(\mathrm{P}=0.0237)$. In vitro, MCP-1 concentration was elevated when monocytes were exposed to MBL. MCP-1 is a potent chemokine, which attracts monocytes and $\mathrm{T}$ cells into the site of infection or immune activation (30). Previous studies have also shown that patients undergoing islet allo-transplantation with low concentrations of MCP-1 have better outcomes such as increased freedom from long-term insulin dependence (31). IL- 6 and IL- 8 are systemic proinflammatory cytokines which are also reduced in MBL deficient patients. Eotaxin, a small molecular cytokine, was slightly raised in normal compared to MBL deficient groups. Another study has suggested this elevation positively correlates with HighMobility Group Box 1 (HMGB1), which is linked to poor clinical outcomes in IAT (23).

\section{Conclusions}

Complement activation is a sensitive intra-operative measurement of inflammation during intra-portal islet infusion and generally normalises by day 7. MBL pathway deficiency is common in recipient patients. Further investigation is merited to explore the detail of complement pathway activity in affected individuals. Therapeutic MBL pathway blockade during and following IAT may improve islet survival and function and thereby clinical outcomes.

Finally, we analysed the correlation between transplant outcomes and MBL functional activity and protein levels. Interestingly, MBL functional activity and MBL protein levels were low in the insulin free group. These results suggest that deficiency of MBL pathway results in a better clinical outcome in IAT. More patients are needed to confirm this finding.

\section{Acknowledgments}

Funding: This work was partially supported by a Diabetes UK Small Grant (BAD 11/0004278; 26/09/2011).

\section{Footnote}

Conflicts of Interest: The authors have no conflicts of interest to declare.

Ethical Statement: The authors are accountable for all aspects of the work in ensuring that questions related to the accuracy or integrity of any part of the work are appropriately investigated and resolved. This study was approved by the institutional review board (IRB), and written informed consent was obtained from all patients included.

Open Access Statement: This is an Open Access article distributed in accordance with the Creative Commons Attribution-NonCommercial-NoDerivs 4.0 International License (CC BY-NC-ND 4.0), which permits the noncommercial replication and distribution of the article with the strict proviso that no changes or edits are made and the original work is properly cited (including links to both the formal publication through the relevant DOI and the license). See: https://creativecommons.org/licenses/by-nc-nd/4.0/.

\section{References}

1. Sutherland DE, Gruessner AC, Carlson AM, et al. Islet autotransplant outcomes after total pancreatectomy: a contrast to islet allograft outcomes. Transplantation 2008;86:1799-802.

2. Takita M, Naziruddin B, Matsumoto S, et al. Implication of pancreatic image findings in total pancreatectomy with islet autotransplantation for chronic pancreatitis. Pancreas 
2011;40:103-8.

3. Sutton JM, Schmulewitz N, Sussman JJ, et al. Total pancreatectomy and islet cell autotransplantation as a means of treating patients with genetically linked pancreatitis. Surgery 2010;148:676-85; discussion 685-6.

4. Webb MA, Illouz SC, Pollard CA, et al. Islet auto transplantation following total pancreatectomy: a longterm assessment of graft function. Pancreas 2008;37:282-7.

5. Ris F, Niclauss N, Morel P, et al. Islet autotransplantation after extended pancreatectomy for focal benign disease of the pancreas. Transplantation 2011;91:895-901.

6. Jung HS, Choi SH, Kim SJ, et al. Delayed improvement of insulin secretion after autologous islet transplantation in partially pancreatectomized patients. Metabolism 2009;58:1629-35.

7. Dong M, Parsaik AK, Erwin PJ, et al. Systematic Review and Meta-analysis: Islet Autotransplantation after Pancreatectomy for Minimizing Diabetes. Clin Endocrinol (Oxf) 2011;75:771-9.

8. Pancreatectomy with Islet Cell Autotransplantation. UPMC Health Plan policy and procedure manual 2010. Available online: http://www.upmchealthplan.com/pdf/ PandP/PAY.077\%20Pancreatectomy\%20w\%20Islet\%20 Cell\%20Autotransplantation\%20Ver\%20July\%2010.pdf

9. Barshes NR, Wyllie S, Goss JA. Inflammationmediated dysfunction and apoptosis in pancreatic islet transplantation: implications for intrahepatic grafts. J Leukoc Biol 2005;77:587-97.

10. Platt JL, Saadi S. The role of complement in transplantation. Mol Immunol 1999;36:965-71.

11. Spirig R, Gajanayake T, Korsgren O, et al. Low molecular weight dextran sulfate as complement inhibitor and cytoprotectant in solid organ and islet transplantation. Mol Immunol 2008;45:4084-94.

12. Takahashi K, Ezekowitz RA. The role of the mannosebinding lectin in innate immunity. Clin Infect Dis 2005;41 Suppl 7:S440-4.

13. Skattum L, van Deuren M, van der Poll T, et al. Complement deficiency states and associated infections. Mol Immunol 2011;48:1643-55.

14. Garred P, Larsen F, Madsen HO, et al. Mannose-binding lectin deficiency--revisited. Mol Immunol 2003;40:73-84.

15. Eisen DP, Minchinton RM. Impact of mannose-binding lectin on susceptibility to infectious diseases. Clin Infect Dis 2003;37:1496-505.

16. Fiane AE, Videm V, Lingaas PS, et al. Mechanism of complement activation and its role in the inflammatory response after thoracoabdominal aortic aneurysm repair.
Circulation 2003;108:849-56.

17. Walsh MC, Bourcier T, Takahashi K, et al. Mannosebinding lectin is a regulator of inflammation that accompanies myocardial ischemia and reperfusion injury. J Immunol 2005;175:541-6.

18. Clayton HA, Davies JE, Pollard CA, et al. Pancreatectomy with islet autotransplantation for the treatment of severe chronic pancreatitis: the first 40 patients at the leicester general hospital. Transplantation 2003;76:92-8.

19. White SA, Davies JE, Pollard C, et al. Pancreas resection and islet autotransplantation for end-stage chronic pancreatitis. Ann Surg 2001;233:423-31.

20. Pollard C, Gravante G, Webb M, et al. Use of the recanalised umbilical vein for islet autotransplantation following total pancreatectomy. Pancreatology 2011;11:233-9.

21. Takita M, Matsumoto S, Noguchi H, et al. One hundred human pancreatic islet isolations at Baylor Research Institute. Proc (Bayl Univ Med Cent) 2010;23:341-8.

22. Koskinen AR, Tukiainen E, Arola J, et al. Complement activation during liver transplantation-special emphasis on patients with atypical hemolytic uremic syndrome. Am J Transplant 2011;11:1885-95.

23. He S, Atkinson C, Qiao F, et al. A complement-dependent balance between hepatic ischemia/reperfusion injury and liver regeneration in mice. J Clin Invest 2009;119:2304-16.

24. Cedzynski M, Atkinson AP, St Swierzko A, et al. L-ficolin (ficolin-2) insufficiency is associated with combined allergic and infectious respiratory disease in children. Mol Immunol 2009;47:415-9.

25. Madsen HO, Satz ML, Hogh B, et al. Different molecular events result in low protein levels of mannan-binding lectin in populations from southeast Africa and South America. J Immunol 1998;161:3169-75.

26. Garred P, Larsen F, Seyfarth J, et al. Mannose-binding lectin and its genetic variants. Genes Immun 2006;7:85-94.

27. Steffensen R, Thiel S, Varming K, et al. Detection of structural gene mutations and promoter polymorphisms in the mannan-binding lectin (MBL) gene by polymerase chain reaction with sequence-specific primers. J Immunol Methods 2000;241:33-42.

28. St Swierzko A, Cedzynski M, Domzalska-Popadiuk I, et al. Mannan-binding lectin-associated serine protease-2 (MASP-2) in a large cohort of neonates and its clinical associations. Mol Immunol 2009;46:1696-701.

29. Bennet W, Sundberg B, Groth CG, et al. Incompatibility between human blood and isolated islets of Langerhans: a finding with implications for clinical intraportal islet 
transplantation? Diabetes 1999;48:1907-14.

30. Fraser DA, Bohlson SS, Jasinskiene N, et al. C1q and MBL, components of the innate immune system, influence monocyte cytokine expression. J Leukoc Biol
2006;80:107-16.

31. Piemonti L, Leone BE, Nano R, et al. Human pancreatic islets produce and secrete MCP-1/CCL2: relevance in human islet transplantation. Diabetes 2002;51:55-65.

Cite this article as: Chung WY, Pollard CA, Stover C, Naziruddin B, Kumar R, Isherwood J, Issa E, Levy MF, Garcea G, Dennison AR. Pilot study: deficiency of mannose-binding lectin-dependent lectin pathway, a novel modulator in outcome from pancreatic islet auto-transplantation. Ann Transl Med 2020;8(5):170. doi: 10.21037/atm.2020.02.19 